\title{
"EL ALMA DE TACNA" \\ O ENSAYO SOBRE LA IDENTIDAD EN \\ JORGE BASADRE Y JOSE JIMENÉZ BORJA
}

Edmundo Motta Zamalloa ${ }^{1}$

\section{RESUMEN}

El artículo inquiere sobre el sentido que Jorge Basadre Grohmann y José Jimenez Borja, siendo jóvenes, dieron al término "alma" en su obra matinal "El Alma de Tacna", escrito y hecho público en 1926 como documento de propaganda para el Plebiscito -que no se llevó a cabo- que definiría la suerte de Tacna y Arica.

\section{INTRODUCCIÓN}

La primera vez que tuve referencia del libro "El Alma de Tacna", que llevaba como subtítulo y entre paréntesis "(Ensayo de interpretación histórica)", escrito por "unos tacneños", seudónimo empleado por dos jóvenes intelectuales emblemáticos de Tacna, Jorge Basadre Grohmann y José Jiménez Borja, publicado en 1926. despertó en mí una gran curiosidad por haberme encontrado con un texto que se ocupaba posiblemente, a saber por el título, de la esencia de un pueblo, de una ciudad, de un departamento, ubicado al sur del Perú. Digo que estaba especialmente interesado porque venía de tropezar con textos similares -de publicación muy posterior a "El Alma de Tacna"- que se interesaban en husmear en el espíritu antes que en la espiritualidad, en hallar la esencia de un pueblo, y que anunciaban en sus correspondientes títulos: "Arequipa: espíritu y materia" (1965), de Manuel Zevallos Vera; "La faz oculta de Arequipa" (1977), del recordado Ántero Peralta
Vásquez, de quienes "El Alma de Tacna" bien podría considerarse precursora; pero era el subtítulo "(Ensayo de interpretación histórica)", lo que marcaba la diferencia significativa de esta obra con respecto a las otras, pues daba cuenta de una manera de encarar el "alma" basaba en la historia. Persistía sin embargo, la inevitable curiosidad por saber acerca de la idea, el sentimiento o motivo que llevó a aquellos célebres jóvenes a estampar el término "alma" en el título de su obra primigenia.

¿De qué se ocupaba "El Alma de Tacna"? ¿Qué entendían los jóvenes Jorge Basadre Grohmann y José Jiménez Borja por "alma" para referirse a Tacna? ¿Acaso un conjunto de ideas que llevaban inevitablemente a un concepto dudoso como "tacneñismo" o "tacneñidad", tal como Peralta Vásquez buscaba definir la "mistianidad" del arequipeño, o en otros ámbitos donde se pretendía entender un posible "cusqueñismo" o "cusqueñidad"? ¿Animaban a Basadre y a Jiménez Borja un prurito regionalista? 
Al abrir las páginas de "El Alma de Tacna" se encuentra con la siguiente estructura: Un esquema Geográfico del departamento de Tacna, seguido de un esquema histórico en la que se ocupa de la historia de Tacna y Arica durante la Colonia, la Independencia Nacional y en la República. La "decadencia" de Tacna bajo la administración peruana. Tacna y Bolivia. A continuación hay una galería de los personajes más representativos de Tacna: Francisco González Vigil (1792-1875), Hipólito Unanue (1755-1833), Francisco Lazo (1823-1869), José Joaquín Inclán (18251880). La obra auroral se ocupa de Tacna y Arica durante la Guerra, y del Cautiverio, la primera época de la chilenización, la insuficiencia de las primeras violencias, el éxodo de la población, un apartado final referente a la "admirable fidelidad" de los tacneños.

Es decir, una cadena de evidencias y episodios compuestos por el territorio-la historia-los personajes emblemáticos-la guerra- el cautiverio, los que puestos en su debido contexto y tomados en conjunto hacen una suerte de "formación discursiva", como la entendía M. Foucault. Al seguir el itinerario de la obra se puede percibir que los jóvenes Basadre y Jiménez Borja, no solo escriben en el título la palabra "Alma" sino que el término es empleado varias veces a lo largo de contextos diferentes, sea para referirse al paisaje, a la historia o a las personas. En concreto, ¿Qué estaban pretendiendo decir con este término? ¿Espíritu? ¿Fuerza? ¿Esencia? ¿ldentidad? ¿Tenía acaso un visaje religioso?

\section{EL ALMA Y LA IDENTIDAD}

Cuando los jóvenes autores escribieron "EI alma de Tacna" (Jorge Basadre tenía 22 años de edad y José Jiménez, 24], el Perú atravesaba una de las coyunturas históricas más importantes de la vida republicana: La Universidad Nacional Mayor de San Marcos, a la que estaban vinculados, vibraba aún por los efectos de la Reforma Universitaria iniciada en 1919 , en la que tomaron parte activa -en particular Jorge Basadre- junto a connotados intelectuales de la Generación del Centenario; la decadencia de la República Aristocrática; las expectativas creadas por la triunfante Revolución Bolchevique en Rusia en 1917; la derrota de la Guerra del Pacífico cuyas consecuencias nefastas para la economía y la política nacionales, mostraban heridas abiertas como la ocupación chilena de territorios peruanos y el sometimiento humillante a cautiverio de sus gentes en Tacna y Arica. Basadre y Jiménez Borja compartían los mismos trazos de una esencial biografía: habían nacido en el territorio ocupado y sufrido los episodios del cautiverio, formado parte del éxodo para salvar la vida, el sueño de "volver" al terruño y sobre todo el afán de formar parte de ese compromiso ineludible que tiene todo patriota al entregarse a la causa de la patria.

Ambos en la infancia fueron al Liceo de Tacna, en Lima para completar los estudios secundarios, Basadre al Colegio Alemán y José Jiménez a "Santo Tomás de Aquino", y al hacerse jóvenes se volvieron a encontrar en San Marcos. Ambos podían agregar que estaban hermanados por la sangre nativa de los Ara: José Jiménez Borja era hijo de José Jiménez Ara, y Jorge Basadre Grohmann era nieto de Concepción Forero y Ara, esposa de Carlos Basadre Izarnótegui.

Como el propio Jorge Basadre se encarga de repasar en La Vida y la Historia, la experiencia en San Marcos fue vital en 
varios sentidos aunque no en la amplitud y profundidad que su temprana vocación por la historia hubiera deseado. Esta fue desarrollándose por una inclinación propia nacida en la biblioteca paterna de la cautiva ciudad natal. En San Marcos compartió inquietudes e ideas con los notables de la época, en la línea de las ideas filosóficas recibió lecciones de Alejando Deustua, Ricardo Dulanto, Alejandro Maguiña, Mariano H. Cornejo, Mariano Iberico. Las lecciones impartidas por Deustua y su sucesor Ricardo Dulanto, lo pusieron en contacto de manera esquemática con el pensamiento del francés Henry Bergson, esquema que, poco después, fue desarrollado ampliamente por Mariano Iberico Rojas.

La filosofía de Henry Bergson era atractiva, pero en especial por su concepción del tiempo, el instante y la duración, no como entidades objetivas sino como parte de la experiencia interior. Hay en él un sentido de presentidad agustiniana del tiempo, según el cual, por ejemplo, no existe el pasado sino el presente pasado. En su teoría, la duración es la extensión del instante. A ello se debe en gran medida que las cosas y los fenómenos son infragmentables, y que la mejor manera de acercarse a su verdad es a través del arte y la empatía. Mariano Iberico halló en tales ideas un gran trasfondo mítico y las volcó, años más tarde, en El espacio humano (1969), Perspectivas sobre El tema del El tiempo (1958), y en particular en ese notable opúsculo llamado Notas sobre el paisaje de la sierra (1973). Iberico al igual que otros pensadores como Víctor Andrés Belaunde, el propio José Carlos Mariátegui, desde perspectivas diferentes, utilizaban los términos "alma" y "esencia" para entender al hombre y la historia del Perú.

La noción de alma por supuesto se remonta mucho más lejos en la historia de las ideas, una de las primeras se relaciona con la idea de principio, como principio de las cosas. Los presocráticos pretendían encontrar en una entidad material lagua, aire, fuego, tierra), algo así como el punto a partir del cual se desprenden todos los puntos, o el punto al que puede reducirse el universo entero. En el Timeo el alma ya no es visto como un principio sino como un ente ideal que se asocia con el cuerpo, y ambos hacen una unidad, a pesar de ser diversos. Esta visión dualista fue cuestionada por Artistóteles, quien concebía el alma como psyche, donde alma y cuerpo convergen en una sola sustancia y se corresponden como la forma y la materia. Esta última concepción entraña la noción de esencia y de fuerza, gracias al cual las cosas hacen un todo y a ello deben su razón de ser. Cuando decimos que los cuerpos y los fenómenos poseen una esencia, estamos queriendo decir que tienen un alma. Pero también se entiende por alma a la fuerza, como la que tienen los cuerpos para desplazarse. Estas dos ideas corrieron distinta suerte a lo largo de la historia. El Timeo dio lugar a los neoplatónicos, a las confesiones de Agustín de Hipona, al idealismo moderno; mientras que la idea aristotélica de alma avanzó dando saltos: Tomás de Aquino, Baruch Spinoza, el realismo filosófico, el existencialismo en sus diversas formas. Hasta un contemporáneo como Gilbert Ryle retomó la inspiración monista: la idea de alma es semejante a un "espectro", como el "espectro en la máquina" lel espectro no es la máquina pero no puede darse sin la máquina). El "alma" supuesto como principio independiente del cuerpo, acabó disolviéndose en un asunto de la psicología, como la subjetividad de la persona.

En la trayectoria religiosa el alma es ante todo un artículo de fe, ligado a distintas 
manifestaciones como el rúaj (en Hebreo equivale a "viento", o "espíritu"). Así el hombre no muere mientras Jehová no le retira su rúaj. Otro sentido inmediato a la religión lo vincula a la sangre como su principio vital.

Para el filósofo alemán G. F.Hegel el alma es la parte inferior de la autoevolución del espíritu, la subjetividad individual que, al escalar a la siguiente etapa, mediante la razón, se vuelve espíritu objetivo, de naturaleza colectiva, que entra en un juego dialéctico con el individuo.

El espíritu objetivo es vital por varias razones, pero la principal está en su condición colectiva pues como pone a descubierto M. Foucault es semejante a una formación discursiva, una particular intersubjetividad que se fragua en cada época semejante al "bosón de Higgs" que hace posible el tránsito de la energía a la materia. Y en el plano cultural hace fraguar una materiaidealidad (M. Godelier) que se expresa en el espíritu de la época.

Pero esta idea acerca del alma que evoluciona hacia una materiaidealidad remite intuitivamente a otro concepto que ha tomado cuerpo al punto de remplazar al de alma; aunque su partida fue diferente, en el curso de su trayectoria llegó a tener una semejante carga semántica. Me refiero a la idea de identidad.

Para la antigüedad clásica, la identidad consiste en estar consigo mismo, y si acaso se formula en relación a otro, la identidad consiste en ser igual al otro. "Identidad" (id. entidad en griego, "ídem" en latín) significa "permanecer en el mismo ser". Los filósofos eleatas, en especial Zenón (V a.C.J, agregarían la idea de "permanecer en el mismo lugar" en su afán de negar la posibilidad del movimiento y reducirla a la condición de apariencia. Pero esta noción de permanecer en el ser o en el lugar, trae como condición la idea de pertenencia, pues aunque parezca de Perogrullo, para permanecer en un lugar antes había que estar en ese lugar, lo cual presupone ideas conexas como el o los vínculos entre el que permanece y el lugar donde permanece. Ambas ideas se ponen en evidencia en El Alma de Tacna: Tacna pertenece a un territorio cuya unidad viene desde la profundidad de la historia. En otra obra de juventud "La multitud, la ciudad y el campo", publicada en 1928, Basadre desarrollará aún más la idea de que el Perú es una unidad en el espacio y una continuidad en el tiempo. Es decir, paisaje e historia, planteada en un enunciado casi axiomático: "Tacna es íntegramente de alma peruana".

\section{EL ALMA EMANA DEL PAISAJE Y DE LA HISTORIA}

La referencia al espacio natural con el que interactúa el hombre es punto de partida de la obra matinal de los jóvenes Basadre y Jiménez Borja, pues no solo es hábitat que alberga la vida sino escenario de la historia y en esa conjunción late la idea de un espacio convertido en paisaje.

"La feracidad de la tierra es en el valle de Tacna excepcional -escriben Basadre y Jiménez-. En general casi no hay retazo de suelo en el departamento que no guarde ricas potencias productivas, pues hasta los cerros arenosos se cubren en la época de "lomas" con una capa de policroma yerba, pero aquí la fecundidad del suelo parece resumir su capacidad de rendimiento. Es tradicional en el sur del Perú el encanto y la esplendidez con que la naturaleza -ayudada con la mano del hombre- ha colmado las chacras de Tacna. Todo género de hortalizas se cosechan. 
Árboles frutales rodean los sembríos. Se juntan, como en un muestrario lujoso de botánica, las más raras especies de plantas. Las de climas tropicales como la palmera y el plátano y las de climas fríos como el pino de Nueva Holanda. La alfalfa alcanza hasta seis cortes por año. El algodón crece silvestre y las propiedades rurales no levantan tapias pues el ganado les hace un compacto y elevado cerco. Casi al fin del valle se encuentra la ciudad de Tacna". (Pág. 14-15).

Una campiña en la que resalta el "paisaje siempre breve", donde el campesino cultiva la parcela de la que es dueño. "El campesino es señor de su tierra, de su hogar, de su espíritu", a diferencia de aquél que es "ganado sufrido e inconsciente que ignora hasta quien es su amo".

Mención especial merecen los valles de Sama y Locumba, aparte del de Tacna y sus pagos, el río Caplina desde su nacimiento en los nevados de Queñuta; las costumbres de labranza, la división agrícola del valle, la repartición del agua de "antigüedad incaica", que hacen afirmar que "la patria es una unidad geográfica, racial y económica" y hacen decir que "Tacna es íntegramente de alma peruana". En "Infancia en Tacna"2, Jorge Basadre ampliará la descripción-memoria de la ciudad-aldea primordial, de aquella naciente urbe que viene ligada con las experiencias de la infancia, la nostálgica Alameda Bolognesi con el sigiloso río

\footnotetext{
${ }^{2}$ Publicado en La vida y la historia; Ensayos sobre personas, lugares y problemas. Segunda Edición revisada y aumentada por el autor. Industrial Gráfica, S.A. Lima.

Aquí encuentra su razón de ser la proximidad del otro que se presenta en st diferencia pero reclama igualdad. Por eso según Tylor la antropologia se define como la ciencia del otro. $Y$ si este conocimiento revierte en el conocimiento de sí mismo, es muy notoria su afinidad a una concepción socrática de la antropología en la forma de enfocar su objeto de estudio y de enmarcar su capacidad como ciencia del otro y como ciencia de lo propio (Geertz). Estas ideas llevan a reflexionar sobre la viabilidad del conocimiento del otro. Conocer es traducir un código por otro código por la vía descriptiva y/o por la via explicativa. Esta forma de conocer plantea serios riesgos, pues el proceso de decodificación se expresa como distorsionante no sólo del código que pretende desentrañar sino de su significado.
}

Caplina que la atravesaba aún cuando estaba a cielo abierto, sus patrióticas palmeras, en fin, sus estrechas y cálidas calles regadas por delgadas acequias; y los nocturnos candiles que daban luz a duendes y apariciones brotando vívidas de la fresca memoria de la abuela.

Este escenario singular al ser interiorizado por el hombre convirtió el espacio en paisaje. Como dice Ortega y Gasset el espíritu del hombre es el paisaje que lleva. En esto reside nuestras diferencias: Al igual que nuestros relojes marcan tiempos diferentes, también son diferentes los paisajes que llevamos en nuestro interior ${ }^{3}$.

Así cada persona lleva el lugar, las cosas y las personas donde y con los que vive. El río y la alameda, como el limeño, el volcán y la campiña como el arequipeño. El paisaje del tacneño está marcado por el desierto, la alameda, el caplina, las bugambillas y particularidades descritas por los jóvenes autores que afloran a la superficie de la sensibilidad del tacneño. El lugar donde todo aquello se encuentra es la base concreta de su suidad. Ortega y Gasset recordaba una práctica común que hacía San Ignacio de Loyola cuando pedía a sus discípulos -durante los Ejercicios Espirituales que hicieran una "composición de lugar" antes de emprender la meditación. La noción subyacente era que el lugar contribuía a fijar las ideas y los sentimientos. Una suerte de paisaje esencial. Ortega y Gasset escribe: "El paisaje es aquello del mundo que existe realmente para cada individuo, es su realidad, es su vida misma. El resto del universo sólo tiene un valor abstracto. $Y$ cada especie animal tiene su paisaje y cada raza de hombre tiene el suyo. No hay un yo sin un paisaje con referencia al cual está viviendo: yo soy aquello que veo y aquello que me hace sentir lo que veo. No hay un yo sin 
un paisaje, y no hay un paisaje que no sea mi paisaje o el tuyo o el de él. No hay un paisaje en general ${ }^{14}$. Esta es la razón que lleva a Ortega al convencimiento de por qué entendemos tan mal a los animales y, algo más grave aun, por qué (los humanos) nos entendemos tan mal los unos a los otros. "No existe, pues, otra manera de comprender íntegramente al prójimo que esforzarse en reconstruir y adivinar su paisaje, el mundo hacia el cual se dirige y con quien está en diálogo vital y viceversa, sólo veremos bien un paisaje que no sea el nuestro buscando con lealtad la pupila que le corresponde, la atalaya única con él orgánicamente enlazada"5.

El paisaje a la vez limita y señala el destino. Es lo que Heidegger denomina paraje, el "adonde de la posible pertinencia de los útiles, tenido desde el principio a la vista por el ver en torno del andar en torno curándose de" ${ }^{\prime 6}$. El término adonde señala el lugar pero también insinúa el punto de llegada, al que están relacionadas las cosas [útiles], abarcados por la mirada, y desde un punto determinado, a partir del cual se produce el desplazamiento -en torno del andar- realizando acciones -curándose de-. Esta demarcación entre el punto de vista y el adonde que configura el horizonte (K. Ulmer] del ser ahí -en este

\footnotetext{
'Ortega y Gasset, ¿Quẻ es un paisaje?, en Obras Completas, V. VII, Madrid, 1975: pág. 144.

Ortegay Gasset, Ob. Cit. Pág: 145.

Heidegger, Ob. Cit. Pág: 118. Al sostener la espacialidad del ser en el mundo escribe "El ser ahí es en el mundo en el sentido del andar en torno, en la familiaridad del curarse de, con los entes que hacen frente dentro mundo". El desplazamiento, que Heidegger llama desalejamiento "es una forma del ser ahi en lo que respecta a su ser en el mundo. No es lejanía (cercanía) ni distancia. Desalejar quiere decir hacer desaparecer la lejanía de algo, es decir, acercamiento". "De esta dirección del ser ahí surgen las direcciones fijas a derechay a izquierda". Pág: 124.

Heidegger, Ob. Cit. Pág: 118 . Sin embargo, Heidegger considera que la espacialidad del ser ahi no es ningún "ser ante los ojos", no puede significar ni nada como un estar en un lugar del "espacio cósmico", ni "ser a la mano" en un sitio" (Pág 120). Seguidamente escribe "De convenirle la espacialidad (al ser ahí) sólo será posible sobre la base de este ser en. En una espacialidad que ostenta los caracteres del des-alejamiento y la dirección" (Pág:120). El "aqui,"alli" y "ahi" no son primariamente puras determinaciones de lugar de los entes intramundanos "ante los ojos" en puntos del espacio, sino caracteres de la espacialidad original del "ser ahi" (136).

"Ortegay Gasset, Ob. Cit. Pág:146.

Ortega y Gasset, Ob. Cit. Pág: 147.
}

caso costeño (podría ser andino o amazónico\}-, con la que se identifica y fija como espacio particular y propio (panorama, según UImer). "La dimensionalidad del espacio es embozada aún en la espacialidad de lo a la mano. El arriba es el en el tejado; el abajo, el en el suelo; el detrás, el a la puerta: todos los dondes son descubiertos e interpretados por el ver en torno a través de las vías y caminos del cotidiano andar en torno, no señalados ni fijados midiendo teoréticamente el espacio"7. De él brota el sentimiento telúrico, esa fuerza que atrae y encadena al paisaje. $Y$ "el patriotismo es ante todo la fidelidad al paisaje, a nuestra limitación, a nuestro destino" ". "Mirad cómo ahora los hombres de Europa luchan por conservar cada cual su paisaje. Mueren esos hombres por evitar que aquellos se apoderen de esta colina, de ese bosquecillo, de esa aldehuela". A Ortega le parecía elocuente que Ramón y Cajal se hiciera biólogo porque le molestaba no encontrar en los libros de biología nombres españoles. "La patria es el paisaje, el paisaje es nuestro ser mismo" ${ }^{\prime 9}$.

\section{"EL AMOR A LAS COSAS PROPIAS ES YA UNA BASE DEL PATRIOTISMO"}

A las notas (de ambiente) dedicadas al territorio y al paisaje que se ha configurado en él, Basadre y Jiménez Borja añaden un carrusel corpóreo de monumentos como el Puerto de Arica, la Iglesia Matriz, el Mercado de Tacna, La Alameda, el viejo órgano (de la Catedral). Una serie de pertenencias -término que se emplea para señalar a los bienes propios- que son tangibles, pero que no se restringen a su condición de cosas, sino que gracias el mecanismo de "congelamiento", contienen, formando parte de la pertenencias, de un modo de ser, de un pensamiento, de un estilo de vida, de un sentimiento.

Ese conjunto corpóreo de identidades 
tangibles que atrapa la memoria de los jóvenes historiadores informan del paisaje urbano de Tacna de los años 1920, y adquieren una dimensión simbólica capaz de con-mover y movilizar el sentimiento. Como todo símbolo une, en términos de materiaidealidad, hechos a sentimientos, cosas a ideas. Está dotado de poder para convocar y conmover. Forma una "identidad cultural comunitaria" que se gesta de manera espontánea, o con esfuerzo y tenacidad, en el curso de la experiencia.

En la búsqueda de una identificación del "alma" de Tacna, no podían faltar aquellos personajes dotados de luz propia que irradiaron su talento más allá de los límites territoriales y del paisaje local y regional. "Los hombres de Tacna", como Francisco de Paula González Vigil (17929-1875), Hipólito Unanue (1755-1833), Francisco Lazo (1823-1869), José Joaquín Inclán (1825-1880), son imprescindibles en la historia del pensamiento, las ciencias, las humanidades, las artes y la política no ya de Tacna sino del Perú. La consistencia de identidad en estos personajes se hallaba vinculada con la asunción de principios y de valores vinculados con la peruanidad ${ }^{10}$.

\section{EL FUEgo SAgRAdO Y LA CRISIS DE ATADURA}

La circunstancia en que fue escrita "El Alma de Tacna" es particularmente relevante, pues como dice Pablo Macera ocurre en una situación de "emergencia social". Tacna era un escenario convulsionado por espadas que se agitaban en sentidos contrarios. La de los invasores que pretendían apropiarse del territorio y someter a sus gentes mediante estrategias persuasivas leducación, enclave de colonias chilenas en suelo peruano], y cuando la persuasión no era

\footnotetext{
"Abelardo Gamarra "el Tunante" fue el primero en emplear la palabra peruanidad en 1929. Fuera del ámbito peruano solo en Argentina se utiliza un vocablo semejante: argentinidad; lo hizo popularjosé Ortega y Gasset en 1931 en una conferencia dictada en ese pais en el centenario de la muerte de Hegel.
}

suficiente se empleaba la violencia desembozada, y del lado contrario la resistencia tenaz y afianzada en el pasado presente y amenazada a la condena del desarraigo absoluto. En esas condiciones "El Alma de Tacna" estaba destinado a servir de propaganda, aunque mejor encaja la de una arenga de guerra, para recuperar Tacna y Arica. Era un documento imprescindible escrito con la pasión enfervorizada de la juventud que recoge y expresa el clamor colectivo para mantener "la continuidad en el espacio" y "la unidad en el tiempo". Necesitaban insistir en el documento, una vez más, sobre qué había que recordar, qué conocer, qué defender y qué recuperar o reivindicar de ese territorio comprendido en una totalidad y ligado a un destino unitario cuyo origen se remontaba al tiempo milenario, a una sangre y a un destino.

El notable documento de propaganda, o mejor de arenga, era una convocatoria dirigida a los compatriotas para recuperar y mantener (permanecer) la identidad. Demostrada la pertenencia a un espacio continuo, sobrevenía simultáneamente la necesidad de permanecer en ella, y ambos sentidos de la identidad se irradiaban al conjunto de hechos y cosas tangibles. En apariencia la identidad podría plantearse contraria a la historia (y hasta transhistórica), ese río temporal hegeliano que fluye sin cesar y que va dejando improntas, o hitos, a su paso. Lo que permanece, como un trozo o un todo, la historia o parte de ella, congelada en la memoria colectiva son esas improntas que se encadenan como puntos o eslabones claves a lo largo del tiempo. La identidad es fundamentalmente histórica. Lo que todavía falta por esclarecer es si lo que permanece es la historia en el ser o es el ser que permanece en la historia.

En sentido estricto la identidad no cambia a pesar de la historia, no cambia la identidad 
del ser, es el ser el que cambia de identidad, toda vez que acumula, adquiere, renueva sin cesar. Al fraguarse la identidad pertenece al pasado y permanece en él, y el pasado no cambia ni se modifica. Por ello resulta falso el dilema de si una cultura debe o no admitir elementos extraños a su organicidad sin poner en riesgo su identidad. Un caso ilustrativo es lo ocurrido con las campesinas del valle Colca (Arequipa). Durante el siglo XVIII, aproximadamente, las mujeres españolas que habían asentado sus reales en Colca, utilizaban una vestimenta con ornamentos que consistían básicamente y frondosamente en bordados. La falda que llevaban hasta los tobillos, al igual que la chaqueta ajustada al busto -corpiño o corsé andino- y el sombrero lucían bellos y recargados bordados que expresaban el espíritu barroco de la época. Con el correr de los años, las campesinas se apropiaron de ese estilo de traje hasta convertirlo, en la actualidad, en un traje que expresa su identidad.

Es fácil imaginar que en la época en que las campesinas, impulsadas por la vanidad femenina de innovarse en el modo de vestir. adaptaban para sí el uso de aquellos vestidos que eran extraños a su cultura y modo de vestir surgieran críticas que acusaban acaso abierta e insolentemente su desidentidad. Tres siglos después, a nadie se le ocurriría reproducir esas críticas, y mucho menos con alguna carga peyorativa. Aquél elemento extraño para el siglo XVIII es hoy un rasgo típico, genuino, auténtico, que expresa de manera inconfundible la identidad de la mujer campesina del Colca. Al igual que en otros lugares en el pasado y en el presente, los elementos que fueron considerados extraños al comienzo terminan por convertirse en una nueva identidad que terminan dando cuenta de una multiidentidad.

Cuando la desidentidad se desenvuelve voluntariamente es tomado hasta como un signo de progreso, sobre todo si lo que atrae se relaciona con una fuente de realización personal o, incluso, colectiva. $\mathrm{Ha}$ ocurrido con el desarraigo voluntario, una tendencia que estuvo presente en la mirada del peruano puesta en la lejanía, dispuesto a correr no pocos riesgos pero listo a marcharse cargado de nostalgias y tristezas. Es diferente al desarraigo compulsivo como ha sucedido en períodos críticos de guerra interna o de pauperización económica en zonas rurales y urbanas. $O$ en época más lejana, durante la colonia, cuando en la llamada cristalización del cristianismo, los españoles emprendieron en los siglos XVI y $\mathrm{XVII}$ una feroz cacería contra los indios bajo la acusación de practicar la idolatría, en campañas cargadas de crueldad que denominaron "extirpación de idolatrías".

Pero en las circunstancias en que se escribe "El Alma de Tacna", más que un desarraigo lo que se estaba poniendo en práctica era un desgarramiento existencial acompañado por el desmembramiento físico de territorio, que iba a producir una grave crisis de atadura con consecuencias psicológicas inevitables para toda una población condenada a cambiar de identidad, de país, de historia, de símbolos; iban a despojarle de un pasado para empezar la vida de cero. La desperuanización emprendida por Chile estaba orientada a destruir la identidad en su doble sentido de pertenencia y permanencia. La desperuanización abrigaba el mismo sentido heidegeriano de desalejamiento, en el que desalejar no significa acercar sino quitar la lejanía. Al desperuanizar se quitaba y destruía lo peruano, aplicando estrategias de "todo vale". La respuesta fue "mantengamos el fuego sagrado" de fidelidad y lealtad a la "patria alejada y soñada" recurriendo al ingenio y al valor en los que se ponía a prueba el amor clandestino con la patria. 
Simultáneamente a la desperuanización se ponía en sentido contrario la práctica de acercamiento al país invasor (chilenización), esto es ofreciendo una nueva pertenencia. Esta medida traía consigo una crisis de reconocimiento, el cual implicaba poder adaptarse a la nueva condición impuesta a ultranza, poder aceptarse en un nuevo espacio, integrarse a otra historia, otra cultura, a una simbólica diferente, a otro paisaje. Los peruanos a quienes se dirigía "El Alma de Tacna" estaban sometidos al contrapunto de ambas crisis, la de atadura y la de reconocimiento.

Jorge Basadre y José Jiménez Borja habían intuido, empezando por la propia experiencia, que primaría la crisis de atadura, pues visualizaban que los invasores estaban encaminados en una empresa cuyo propósito era difícil de conseguir porque latía en el peruano hondura histórica y unidad territorial, elementos fundamentales del "alma" de Tacna, pues el alma, como pensaban los clásicos era principio y fuerza, inseparable el cuerpo del espíritu, sustancia única, unidad de territorio e historia.

\section{REFERENCIAS BIBLIOGRÁFICAS}

Basadre Grohmann, Jorge y José Jiménez Borja ["Unos Tacneños"] 1926 Alma de Tacna, Ensayo de interpretación histórica. Ediciones Cofide, Tacna.

Basadre Grohmann, Jorge1929 La multitud, la ciudad y el campo en la Historia del Perú. Ediciones treintaitrés \& Mosca Azul editores. Lima.1981 La Vida y la Historia. Ensayos sobre persona, lugares y problemas. Segunda Edición revisada y aumentada por el autor. Lima.
Peruanidad (selección). Instituto Riva Agüero, PUC. Lima. Selección de textos tal como aparecieron en la edición de 1957.

Foucault, Michel 1976 La arqueología del saber. Traducción de Aurelio Garzón del Camino. Siglo veintiuno editores, Argentina. Tercera Edición.

Heidegger, Martín 1971 El ser y el tiempo. Fondo de Cultura Económica. México.

Lecaros, Fernando 1983 El joven Basadre. Ediciones rikchay Perú, Lima.

Ortega y Gasset, José 1975 ¿Qué es el paisaje?, en Obras Completas, Vol. VII, Madrid.

Macera D'allorso, Pablo 1983 Las furias y las penas [entrevistas]. Mosca Azul Editores, Lima.

Peralta Vásquez, Ántero 1977 La faz oculta de Arequipa, Ari-kepa (detrás del cerro]. Arequipa.

Ulmer, Karl 1965 El objeto de la filosofía. Editorial Herder, Barcelona.

Zevallos Vera, Manuel 1965 Arequipa, espíritu y materia. Arequipa.

Zubiri, Xavier 1996 E s p a c i o. Tiempo. Materia. Alianza editorial, Madrid.

\section{Correspondencia}

Edmundo Motta Zamalloa parmenides5ac@hotmail.com 